\title{
'Yorizane': A New Self-compatible Almond Cultivar Suitable for California Production
}

\author{
Craig A. Ledbetter \\ U.S. Department of Agriculture, Agricultural Research Service, Crop Diseases, \\ Pests \& Genetics Research Unit, 9611 S. Riverbend Avenue, Parlier, CA \\ 93648-9757
}

Additional index words. breeding, kernel quality, kernel defects, Prunus dulcis, self-fertile

\section{Origin}

'Yorizane', tested as Y116-161-99, was one of 131 siblings field-planted during 1999 from seedling population 985001 . The population resulted from the hybridization of 'Tuono' (self-compatible) $\times$ Agricultural Research Service almond selection 74-48 (self-incompatible), performed in Parlier, CA (Fig. 1). Seedlings were screened initially for self-compatibility using insect-proof bags installed on preanthesis fruiting branches. 'Yorizane' was among many seedlings having fruit set after self-pollination. The degree of fruit set on the bagged 'Yorizane' branches and observed close proximity of anthers and stigmatic surfaces on open flowers provided evidence of its self-fertility. 'Yorizane' was selected for further evaluation in 2003 for its attractive kernel characteristics and apparent heavy yield.

\section{Description and Performance}

Descriptors compiled by Bioversity International (Gülcan, 1985) have been used to characterize the new cultivar. Seventeen traits involving phenology, tree morphology, and nut characteristics have been evaluated for 'Yorizane' and compared with 'Nonpareil' (Table 1). Further characterization has been accomplished through shelling experiments after harvest. Yield quantification and kernel

Received for publication 18 June 2021. Accepted for publication 8 July 2021.

Published online 18 August 2021.

Appreciation is extended to the Almond Board of California for their support of the Regional Variety Trials (RVTs). Gratitude is expressed to Bruce Lampinen for organizing and providing RVT data as well as to University of California Farm Advisors Roger Duncan, Phoebe Gordon, and Luke Milliron for managing the RVT orchards. The expertise of Julia Halász and Attila Hegedús is credited in providing the $S$-allele genotype for 'Yorizane'.

Mention of tradenames or commercial products in this publication is solely for the purpose of providing specific information and does not imply recommendation or endorsement by the U.S. Department of Agriculture.

C.A.L. is the corresponding author. E-mail: craig.ledbetter@ars.usda.gov.

This is an open access article distributed under the CC BY-NC-ND license (https://creativecommons.org/licenses/by-nc-nd/4.0/). quality defects have been obtained from trees included in the Regional Variety Trials (RVTs) conducted at three sites in the San Joaquin Valley.

A comparison of kernel physical characteristics between 'Nonpareil' and 'Yorizane' is presented in Table 2. Kernels of 'Yorizane' have slightly more mass and are slightly longer and wider than 'Nonpareil' kernels. These size differences led to significant changes in the dimensional ratios, with 'Yorizane' having a length:width ratio somewhat smaller than 'Nonpareil', and both length:thickness and width:thickness ratios being larger than 'Nonpareil'. These differences in dimensional ratios affect kernel appearance relative to resemblance with 'Nonpareil' kernels (Fig. 2), and when examined aggregately, 'Yorizane' kernels clearly fall outside the boundaries of phenotypic variability for the Nonpareil Marketing Group. Multivariate analyses based on kernel dimensions and pellicle color have been used effectively to distinguish kernels representing the Nonpareil, California and Mission Marketing groups (Ledbetter and Sisterson, 2013). Kernels of 'Yorizane' blanch easily and should be promoted in the California Marketing Group.

'Yorizane' kernels are easy to remove from the shell, and crackout has averaged $\approx 67 \%$ across harvests. Shelling performance has been examined over a 5 -year period using a research-size roller-cracker (Ledbetter and Palmquist, 2006). The percentage of whole, undamaged kernels shelled from nonhulled field-dried nuts was significantly greater $[t(18)=4.21, P<0.001]$ for 'Yorizane' than for 'Nonpareil' (22.3 $\pm 0.7 \%$ vs. $19.7 \pm$ $1.9 \%$, respectively).

The new almond has been part of the 2014-planted RVTs in which yield, kernel quality, and horticultural characteristics are being evaluated for 30 almond cultivars and advanced selections in Butte, Stanislaus, and Madera County orchards (Gordon et al., 2020; Lampinen, 2021). Currently, RVT orchards have completed their fifth harvest, with almond accessions varying widely in kernel yield. The Madera site has provided both the highest and lowest cumulative yields of trialed accessions, ranging from 12,009 $\mathrm{kg} \cdot \mathrm{ha}^{-1}$ ('Nonpareil') to $3515 \mathrm{~kg} \cdot \mathrm{ha}^{-1}$ [advanced selection University of California at Davis (UCD) 3-40] after the fifth harvest.

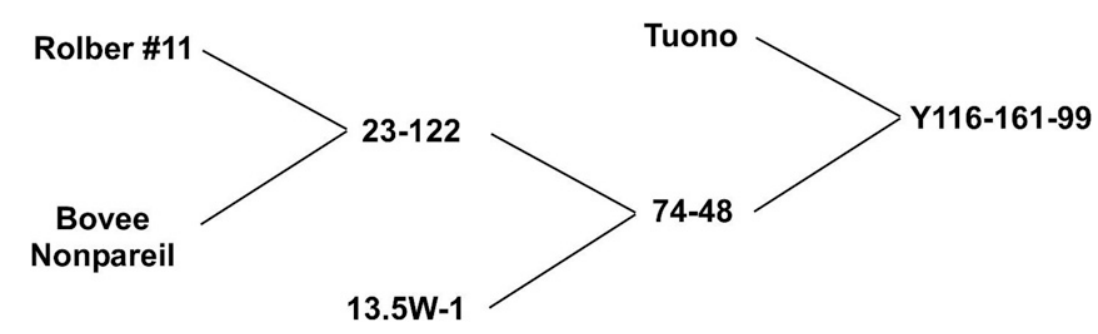

Fig. 1. Parentage of 'Yorizane' (Y116-161-99) almond.

Table 1. Characterization of various 'Yorizane' almond traits relative to those of 'Nonpareil' referenced in the Bioversity International descriptor list for almond.

\begin{tabular}{llll}
\hline & & \multicolumn{1}{c}{ Expression of trait } \\
\cline { 3 - 4 } Descriptor no. $^{\mathrm{z}}$ & \multicolumn{1}{c}{ Trait } & \multicolumn{1}{c}{ Yorizane } & \multicolumn{1}{c}{ Nonpareil } \\
\hline 4.2 .1 & Season of flowering & Intermediate & Intermediate \\
4.2 .2 & Harvest maturity & Early & Early \\
4.3 .2 & Kernel shape & Broad & Intermediate \\
6.1 .1 & Tree habit & Drooping & Spreading \\
6.1 .2 & Tree vigor & Intermediate & Intermediate \\
6.1 .5 & Foliage density & Low & Low \\
6.2 .2 & Duration of flowering & Avg $=9$ d & Avg $=9$ d \\
6.2 .6 & Color of petals & White & White \\
6.2 .7 & Double flowers in buds & Few & Few \\
6.2 .13 & Nut shape & Oblong & Cordate \\
6.2 .15 & Marking on outer shell & Intermediate & Sparsely pored \\
6.2 .16 & Suture opening of the shell & Excellent seal & Open \\
6.2 .17 & Shell retention & All retained & Partly missing \\
6.2 .18 & Softness of shell & Soft & Paper \\
6.3 .2 & Shriveling of kernel & Slightly wrinkled & Slightly wrinkled \\
6.3 .3 & Kernel pubescence & Low & Low \\
10 & S-genotype & $S_{\mathrm{f}} S_{5}$ & $S_{7} S_{8}$ \\
\hline $\mathrm{z}$ As refered & in & &
\end{tabular}

${ }^{\mathrm{z}}$ As referenced in Gülcan (1985). 
Table 2. Physical characteristics of 'Nonpareil' and 'Yorizane' almond kernels grown in Parlier, CA, from 2012 through 2019.

\begin{tabular}{lcc} 
Character & Nonpareil & Yorizane \\
\hline No. of kernels evaluated & 3030 & 1306 \\
Kernel weight $(\mathrm{g})$ & $0.99 \pm 0.2$ & $1.06 \pm 0.1$ \\
Kernel length $(\mathrm{mm})$ & $22.2 \pm 1.5$ & $23.0 \pm 1.6$ \\
Kernel width $(\mathrm{mm})$ & $12.0 \pm 0.9$ & $13.5 \pm 1.0$ \\
Kernel thickness $(\mathrm{mm})$ & $7.8 \pm 0.5$ & $7.7 \pm 0.6$ \\
Length:width ratio & $1.87 \pm 0.58$ & $1.71 \pm 0.08$ \\
Length:thickness ratio & $2.86 \pm 0.25$ & $3.04 \pm 0.43$ \\
Width:thickness ratio & $1.54 \pm 0.15$ & $1.78 \pm 0.63$ \\
Pellicle luminosity & $51.4 \pm 3.9$ & $53.0 \pm 3.2$ \\
Pellicle chroma & $43.2 \pm 2.6$ & $47.7 \pm 2.6$ \\
Pellicle hue $\left(^{\circ}\right)$ & $68.2 \pm 2.8$ & $69.1 \pm 1.9$ \\
\hline
\end{tabular}

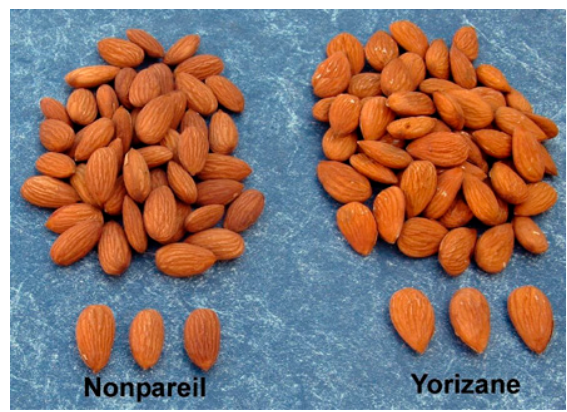

Fig. 2. Appearance of 'Nonpareil' and 'Yorizane' kernels.

Collectively, the Stanislaus orchard exhibited the lowest yields of the three RVT sites. Cumulative kernel yield of 'Yorizane' ranged from $11,614 \mathrm{~kg} \cdot \mathrm{ha}^{-1}$ (Madera site) to 7106 $\mathrm{kg} \cdot \mathrm{ha}^{-1}$ (Stanislaus site) after the fifth harvest. Cumulative kernel yield of 'Nonpareil' was significantly greater than 'Yorizane' at the Butte orchard, but yields have not differed significantly at the Stanislaus or Madera orchards after five consecutive harvests. Comparison of 'Nonpareil' and 'Yorizane' kernel yields during the five harvests at the three RVT sites is presented in Fig. 3.

The biennial bearing index (Hoblyn et al., 1937) has been calculated from annual almond yields in the RVTs using harvest data from 2016 through 2020 . This index varied between locations for 'Yorizane', ranging from 0.30 at the Butte orchard to 0.08 at the Madera site. Across locations, biennial bearing indices for 'Nonpareil' were slightly greater than those for 'Yorizane', averaging 0.27 and 0.22 , respectively. The tendency to alternate-bear in 'Nonpareil' ranged from 0.40 (Stanislaus site) to 0.16 (Madera site).

A wide range of kernel defects have been evaluated in the RVT plots during the past three harvests. Double, twin, and blank kernels were not detected in 'Yorizane' kernel samples during these harvests. Kernels identified as having naval orangeworm (Amyelois transitella) damage were absent in both 'Nonpareil' and 'Yorizane' samples, indicating appropriate
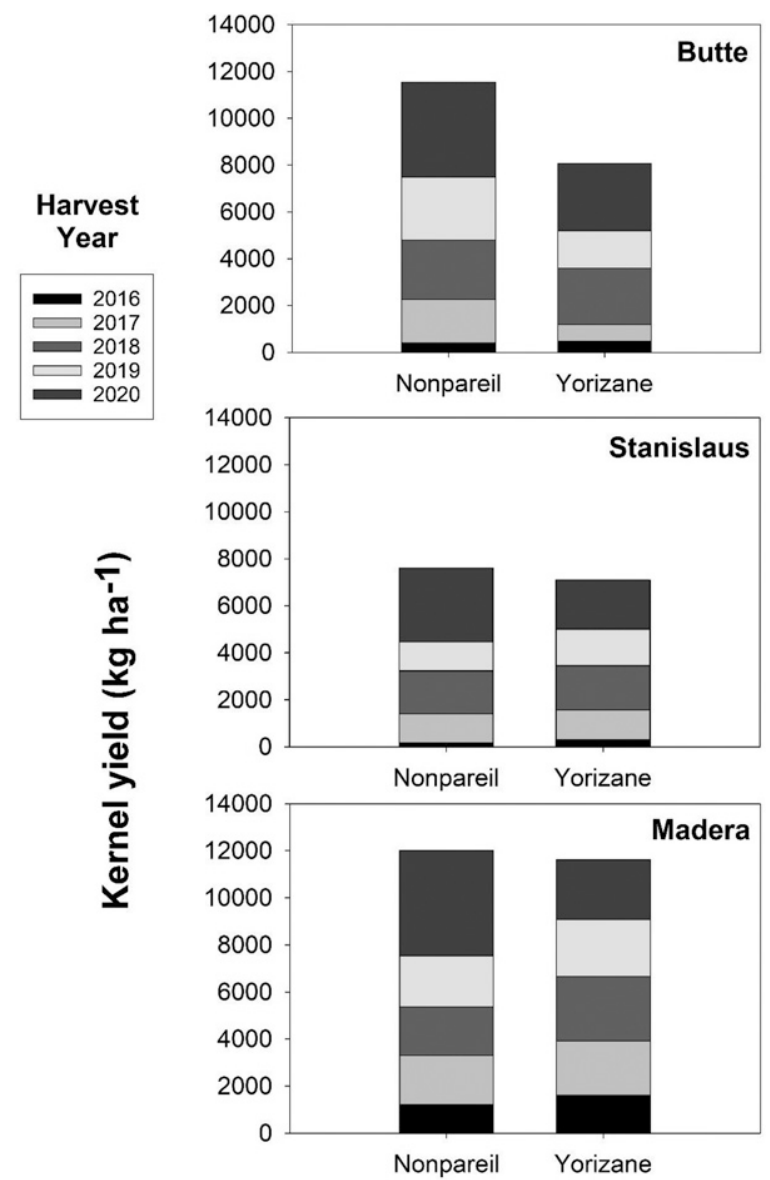

Fig. 3. Cumulative kernel yields (2016-20) of 'Nonpareil' and 'Yorizane' almond from 2014-planted Regional Variety Trial orchards in California's San Joaquin Valley.

insect management steps were taken before those harvests. Kernels with excessive creases, ruptured kernels, and with either mold or gumming were also absent in 'Yorizane' kernel samples. Notable defects of 'Yorizane' kernels include shriveled kernels ( $8 \%$ to $9 \%$ in samples from the RVT Butte plot) and kernels with stain or discoloration. Stained/discolored 'Yorizane' kernels amounted to $6 \%$ to $21 \%$ of samples obtained from the 2020 harvest across all three RVT orchards.

\section{Availability}

'Yorizane' has been indexed by the Foundation Plant Services, University of California, Davis, and found free of known viruses. The new cultivar is not licensed and is available to all interested growers. In Jan. 2021, it was provided to California commercial almond nurseries for future development of orchard trees. Inquiries regarding availability of 'Yorizane' should be addressed to Craig Ledbetter (craig. ledbetter@usda.gov), San Joaquin Valley Agricultural Sciences Center, 9611 S. Riverbend Avenue, Parlier, CA 93648. It is requested that appropriate recognition be made if this cultivar contributes to the development of a new breeding line or cultivar.

\section{Literature Cited}

Gordon, P., R. Duncan, L. Milliron, and B. Lampinen. 2020. Field evaluation of almond varieties: A look at regional trial results through sixth leaf. West Coast Nut, Fresno, CA.

Gülcan, R. 1985. Descriptor list for almond (Prunus amygdalus). Rev. ed. International Board for Plant Genetic Resources (Bioversity International), Rome, Italy.

Hoblyn, T.N., N.H. Grubb, A.C. Painter, and B.L. Wates. 1937. Studies in biennial bearing. J. Pomol. Hort. Sci. 14:39-76, doi: 10.1080/0368 3621.1937.11513464.

Lampinen, B. 2021. Field evaluation of almond varieties. Almond Board of California project no. 17-Hort2 annual research report. Almond Board of California, Modesto, CA.

Ledbetter, C.A. and D.E. Palmquist. 2006. Comparing physical measures and mechanical cracking products of 'Nonpareil' almond (Prunus dulcis [Mill.] D.A. Webb.) with two advanced breeding selections. J. Food Eng. 76:232-237, doi: 10.1016/j.jfoodeng.2005.04.046.

Ledbetter, C.A. and M.S. Sisterson. 2013. Distinguishing Nonpareil marketing group almond cultivars through multivariate analyses. J. Food Sci. 78(9):1430-1436, doi: 10.1111/1750-3841.12179. 